\title{
AVANCES EN CLASIFICACIÓN DE SISTEMAS DE PRODUCCIÓN CON BOVINOS DOBLE PROPÓSITO EN COLOMBIA
}

\author{
ADVANCES IN CLASSIFICATION OF PRODUCTIONSYSTEMS \\ WITH DUAL PURPOSE BOVINE IN COLOMBIA
}

Cortés-Mora, J.A. ${ }^{1}$; Cotes-Torres, A. ${ }^{2 *}$ y Cotes-Torres, J.M. ${ }^{3}$

\begin{abstract}
${ }^{1}$ Grupo de Investigación en Administración y Economía de Cadenas de Agronegocios (GIAECA). Universidad Nacional de Colombia. Bogotá, D.C. Colombia. jacortesm@unal.edu.co

${ }^{2}$ Departamento de Ciencias para la Producción Animal. Facultad de Medicina Veterinaria y de Zootecnia. Universidad Nacional de Colombia. Bogotá, D.C. Colombia. *acotest@unal.edu.co

${ }^{3}$ Departamento de Agronomía. Facultad de Ciencias Agrarias. Universidad Nacional de Colombia. Medellín. Colombia.jmcotes@unal.edu.co
\end{abstract}

\section{Palabras clave adicionales}

Desarrollo. Ganadería. Llanuras tropicales.

\section{RESUMEN}

El objetivo de la investigación es clasificar y presentar algunas características de los sistemas de producción bovina en el Piedemonte Llanero de Departamento del Meta y del sur del Casanare. Para tal fin, se seleccionaron 14 explotaciones representativas de la región. Para clasificar los sistemas de producción se empleó un análisis de conglomerados. De esta forma, se obtienen tres tipologías de sistemas de producción bovina, así: 1) Tradicional, el cual tiene una baja capacidad empresarial y tecnológica; 2) Mejorado, el cual tiene una moderada capacidad empresarial y tecnológica y 3) Intensivo, que cuenta con alta capacidad empresarial y tecnológica. Los tres sistemas de producción encontrados, complementan los trabajos de otros investigadores y contribuye a tener parámetros de gestión tecnológica para el desarrollo de las ganaderías de la región.

\section{SUMMARY}

The aim of the research is to classify and show some features of the bovine production systems in Piedemonte Llanero of Meta Department and South of Casanare. For this purpose, we selected 14 farms representative of the region. To classify production systems we used a cluster analysis. Thus, we obtained three types of

\section{AdDitional KEYWORDS}

Development. Livestock. Tropical plains.

production systems: 1) Traditional, which has a low economic-business and technological capacity; 2) Improved, which has a moderate economic-business and technological capacity and 3) Intensive, which has high economic-business and technological capacity. These production systems complement the works of others researchers and it helps to have parameters for technology management and the development of farms in the region.

\section{INTRODUCCIÓN}

El estudio de clasificación de Arias et al. (1990) constituyó uno de los principales trabajos realizados en Colombia que buscó caracterizar los principales sistemas de producción, reconociendo que si bien todas las explotaciones son diferentes, existen factores que prevalecen en cada una de ellas y que permiten caracterizar su comportamiento. Sin embargo, aunque Arias et al. (1990) presentaron algunos parámetros empleados en cada sistema para Colombia, también dejaron de manifiesto la necesidad de precisar estos parámetros en cada una de las regiones del país. 


\section{CORTÉS-MORA, COTES-TORRES Y COTES-TORRES}

Es así como el presente trabajo clasifica y describe algunas de las características de los sistemas de producción con bovinos doble propósito del piedemonte de los Llanos Orientales de Colombia.

\section{MATERIAL Y MÉTODOS}

El estudio se llevó a cabo en el piedemonte del Departamento del Meta y en el sur del Departamento del Casanare de Colombia, en la zona de vida clasificada como Bosque Húmedo Tropical la cual cuenta con una precipitación promedio de 2600 $\mathrm{mm}$ anuales y una temperatura promedio de $26^{\circ} \mathrm{C}$. La región está ubicada entre $2^{\circ}$ y $5^{\circ} \mathrm{de}$ latitud Norte, con una altitud entre 100 y 300 m.s.n.m. La época seca es de diciembre a marzo, los meses restantes son de lluvia intensa, la humedad relativa oscila entre 65 y $80 \%$. La zona tiene varias clases de suelos con pendientes moderadas, bien drenados y pedregosos con limitaciones para uso ganadero.

A través del Comité de Ganaderos se seleccionaron 14 explotaciones representativas de la región y se realizaron visitas técnicas que se complementaron con encuestas a profundidad con cada uno de los administradores o propietarios de las explotaciones, con lo cual se aseguró la confiabilidad de la información recolectada. Cada encuesta estuvo conformada por 167 preguntas que recopilaban información sobre alimentación, genética y reproducción, gestión, instalaciones y equipos, manejo zootécnico, manejo de praderas, sanidad y bienestar social.

A partir de los trabajos de Young (1981) y Winsberg y Ramsay (1983) se utilizó el procedimiento PRINQUAL del software estadístico SAS para transformar todas las variables cualitativas en cuantitativas y luego realizar la clasificación de los sistemas utilizando un análisis de conglomerados a través de la Distancia de Mahalanobis. Posteriormente se utilizó el método de enlace simple, como un método de agrupamiento válido (Díaz, 2002). Finalmente, con el fin de definir el número de conglomerados por seleccionar se empleó el $\mathrm{PST}^{2}$ o seudoestadístico t ${ }^{2}$, (Hair et al., 2005; Cooper y Milligan, 1988.

\section{RESULTADOSYDISCUSIÓN}

Teniendo en cuenta la metodología anterior, el $\mathrm{PST}^{2}$ con tres conglomerados fue de 5,8, mientras que con dos conglomerados ascendió a 11,2, y con un conglomerado descendió a 3,6. Dado que el número de conglomerados más adecuado es el inmediatamente anterior a un ascenso abrupto en los valores de $\mathrm{PST}^{2}$, se decidió seleccionar tres conglomerados como el número más apropiado de agrupación. De esta forma se identificaron 3 grupos de sistemas a los cuales se denominó así: 1) Sistema de producción tradicional (SPT); 2) Sistema de producción mejorado (SPM) y 3 ) Sistema de producción intensivo (SPI).

De esta forma, se puede afirmar que SPT representa al 78,55\% de las explotaciones de la zona, pero sus propietarios no acostumbran a registrar información técnica ni económica. Algunos de ellos, registran de manera eventual datos de partos e ingresos; sin embargo, ninguno conoce los costos de su producción ni hacen planeamiento de sus explotaciones. Generalmente se permite a la vaca alimentar de manera exclusiva por más tiempo al becerro, disminuyendo el tiempo de lactancia, el cual fluctúa desde 90 hasta 210 días, no obstante, durante el tiempo de amamantamiento restringido no se suplementa. La genética se fundamenta en el uso de animales adaptados con un alto porcentaje de genes Bos indicus. El sistema de servicios comúnmente utilizado es la monta natural, bajo un esquema extensivo que no permite la programación de montas ni de partos. Se realizan diagnósticos reproductivos de manera eventual, generalmente para vender animales o por incertidumbre en el estado de gestación de alguna vaca. 


\section{CLASIFICACIÓN DE SISTEMAS DE PRODUCCIÓN BOVINA EN COLOMBIA}

El sistema de alimentación se fundamenta en el uso de pasturas. En muy pocas explotaciones se realizan análisis de suelos y en ninguna de ellas se aplican programas de fertilización. El suministro de sales es la única estrategia nutricional. Los animales en levante no se suplementan, lo que se refleja en retrasos en la edad al primer servicio de las novillas y en el tiempo requerido para obtener pesos al sacrificio de machos. No se practican métodos de conservación de forrajes, a pesar de que todos estos productores expresan tener problemas para alimentar al ganado en época seca. En general las explotaciones cuentan con corral de manejo, manga y embarcaderoy en algunas de ellas se tiene también establo de ordeño y corrales para terneros. Bajo las anteriores condiciones, se obtienen 3,88 litros/vaca/ día, en un ordeño diario que se realiza siempre de forma manual.

En cuanto a SPM, representa el 14,30\% de las explotaciones analizadas y es un sistema de mediana capacidad empresarial y tecnológica. Las variables de gestión indican que estos productores manejan la información de manera similar a los de SPI, las mayores diferencias encontradas en este aspecto están en la eficiencia del mecanismo de registro empleado (SPI es algún software comercial, mientras que en SPM son los libros y comprobantes contables) y en el tipo de información registrada que generalmente se limita a costos parciales, algunos eventos reproductivos y de manejo de praderas. No obstante, en este tipo de sistema, es frecuente el cálculo de indicadores, que permiten la adecuada toma de decisiones para un mejoramiento continuo del sistema. En algunos casos, se realiza programación de actividades de tipo productivo (vermifugaciones, vacunaciones). La duración de la lactancia es mayor a la observada en SPT, ubicándose desde 210 hasta 270 días y los becerros en amamantamiento restringido cuentan con una ración de ensilaje o alimento balanceado comercial. La alimentación se fundamenta en el uso de pasturas, con un manejo mejorado de las mismas (análisis de suelos y fertilización), se suministra de manera permanente minerales a la totalidad del hato, y en algunas ocasiones forrajes en estado de conservación y otros de mayor valor nutricional (generalmente subproductos de la palma y del arroz). Los animales en levante se alimentan de manera tradicional (pasto y sal mineral), sin embargo, se destetan con una mejor conformación que los de SPT. La genética se fundamenta en el uso de animales adaptados con una alta proporción de genes Bos indicus; sin embargo, algunas explotaciones cruzan sus vacas con toros que tienen alguna proporción de genes Bos taurus. En este sistema se cuenta con una programación de montas naturales y diagnóstico reproductivo. Se encontró que estas explotaciones cuentan con mejores condiciones de instalaciones y equipos, ya que disponen de equipos mecánicos para el ordeño y tractor con implementos para la renovación de pasturas y su producción láctea es de 7,15 litros/vaca/día.

Finalmente SPI agrupa al 7,15\% de los productores y es el que cuenta con la mejor capacidad empresarial y tecnológica. Las variables de gestión que mejor permiten visualizar las condiciones diferenciales de este sistema, hacen referencia a la eficiencia en la toma de información de tipo zootécnico, como por ejemplo parámetros en reproducción, producción, manejo de praderas, análisis de la estructura de costos, programación de actividades de tipo productivo a lo largo del año, y cálculo de indicadores que permiten diagnosticar de manera precisa la realidad de la explotación y tomar decisiones acertadas. Los sistemas de alimentación se fundamentan en el uso de pasturas, con un manejo más eficiente de las mismas, sin embargo, se complementan las dietas con el uso de subproductos de cosecha de cultivos de arroz y palma, forrajes en estado de conservación (ensilajes), en algunos casos alimentos balanceados comerciales o fabricados en la misma finca y suministro de minerales de manera permanente. El impacto 


\section{CORTÉS-MORA, COTES-TORRES Y COTES-TORRES}

de todas estas prácticas zootécnicas se observa en varios aspectos del sistema; en primer lugar en su producción de leche que utilizando ordeño manual esta alrededor de 7,50 litros/vaca/día, siendo la mayor de los tres sistemas estudiados; en segundo lugar tienen mejores condiciones de conformación y desarrollo sexual de las hembras y en caso de tener machos, en mejores tasas de crecimiento y menor tiempo requerido para obtener pesos de sacrificio y en último lugar se optimiza el uso del terreno al permitir aumentos en la carga animal de las explotaciones. El uso de razas Bos taurus se hace para mejorar la genética disponiblepor medio de programas de inseminación artificial. Todas estas prácticas junto con el uso apropiado y eficiente de las instalaciones y equipos disponibles, permite calificar a este sistema de producción como el más productivo de los analizados en condiciones de piedemonte del Meta y sur del Casanare.

\section{CONCLUSIONES}

E1 92,85\% de los sistemas de producción con bovinos doble propósito del piedemonte del Departamento del Meta y del sur del Departamento del Casanare en Colombia están en un sistema SPT o SPM; ambos

\section{BIBLIOGRAFÍA}

Arias, J.; Balcázar, A. y Hurtado, R. 1990. Sistemas de producción bovina en Colombia. Coyuntura Agropecuaria, 6: 85-119.

Cooper, M.C. and Milligan, G.W. 1988. The effect of error on determining the number of clusters. In: W. Gaul y M. Schader (Eds.). Data, expert knowledge and decisions. Springer Berlin Heidelberg. pp. 319-328.

Díaz, G. 2002. Estadística multivariada: inferencia y metodología. Universidad Nacional caracterizados por un uso bastante limitado de las tecnologías en producción animal, lo cual genera índices de productividad inferiores a los biológicamente posibles en la región. En contraposición a lo anterior, está el sistema SPI que consigue mayores productividades a partir de un enfoque zootécnico del uso de los recursos disponibles fundamentado principalmente en estrategias de gestión empresarial ganadera; las cuales solo son posibles en la medida que los ganaderos tengan condiciones de seguridad para invertir y administrar sus explotaciones.

Finalmente, es justo mencionar que uno de los limitantes del estudio es el hecho de que solo se logró obtener la información de 14 explotaciones; por eso se recomienda para futuras investigaciones ampliar la base de explotaciones involucradas en este tipo de estudios.

\section{AGRADECIMIENTOS}

Los autores agradecen a TecniganVillavicencio (adscrito al Comité de Ganaderos del Departamento del Meta) y a los ganaderos del Departamento del Casanare, por el apoyo logístico brindado para llevar a cabo esta investigación.

de Colombia. Bogotá. Colombia.

Hair, J.F.; Anderson, R.E.; Tatham, R.L. y Black, W. 2005. Análisis multivariante. Pearson-Prentice Hall. Madrid. España.

Winsberg, S. and Ramsay, J.O. 1983. Monotone spline transformations for dimension reduction. Psychometrika, 48: 575-595.

Young, F.W. 1981. Quantitative analysis of qualitative data. Psychometrika, 46: 357388 . 